\title{
Removal of Organic Pollutant from Aqueous Solution by Rice Husk Activated Carbon (RHAC)
}

\author{
Sabrina Khan, Zannatul Ferdous Raha, Mahe Jabeen, Mahe Rukh, SyedaTanzila Reza, Easir A Khan* \\ Department of Chemical Engineering, Bangladesh University of Engineering and Technology, BUET, Dhaka, \\ 1000, Bangladesh, "Email: eakhan@che.buet.ac.bd
}

Abstract:

In this work, activated carbon was prepared from low cost agricultural by-product rice husk and $\mathrm{NaOH}$ was used as chemical activating agent. The characterization of rice husk activated carbon (RHAC) was performed by Scanning Electron Microscope (SEM) and BET surface analyzer. In addition, the proximate analysis and Boehm titration was conducted to investigate RHAC properties and surface function groups. The adsorption of an organic pollutant (phenol) using RHAC was studied by the batch method. It was established that phenol adsorption by RHAC reached equilibrium at about $2640 \mathrm{~min}$ and is more compatible with Langmuir adsorption isotherm with respect to Freundlich isotherm. Phenol adsorption capacity of RHAC was found to be $17.123 \mathrm{mg} \mathrm{g}^{-1}$. The phenol adsorption kinetics corresponds well with pseudo first order model.

Keyword: Adsorption separation, Phenol, Activated carbon and Rice husk

\section{Introduction}

Many industrial wastes contain refractoryorganics which are almost impossible to remove by conventional biological treatment processes [1]. Phenols as a class of organics are similar in structure to the more common herbicides and insecticides, resistant to biodegradation, besides the effect of their presence in water supplies, are noticed as bad taste and odour [2]. For example, phenols form undesirable 'chlor-phenol' ora medicinal taste in the presence of chlorine. As a result, these compounds can exert negative effects on different biological processes. Consequently, phenolics were considered to constitute the 11 th of the 126 chemicals which have been designated as priority pollutants by the Environmental Protection Agency in the U.S. [3].Phenolic derivatives belong to a group of common environmental contaminants. The presence of their even low concentrations can be an obstacle to the use (and/or) reuse of water. Most of these compounds are recognized as toxic carcinogens. Industrial sources of contaminants such as oil refineries, coal gasification sites, and petrochemical units generate large quantities of phenols. Besides, phenolic derivatives are widely used as intermediates in the synthesis of plastics, colours, pesticides, insecticides, etc. Degradation of these substances means the appearance of phenol and its derivatives in the environment. Phenols have weak acidic properties.

In water treatment, the most widely used method of phenol removal is adsorption onto the surface of active carbon [4]. Activated carbons remove many of the impurities occurring in water; small organic molecules with low solubility have sizes in the range of $0.6 \pm 0.8$ $\mathrm{nm}$ and can be adsorbed in micropores; colour bodies and humic acids have dimensions $(1.5 \pm 3.0 \mathrm{~nm})$ that will favour their adsorption in mesopores[5]. The adsorption capacity of a given carbon is a function of (i) porous structure, (ii) chemical nature of the surface, and (iii) $\mathrm{pH}$ of the aqueous solution. On the other hand, the adsorption process will be influenced by the nature of the sorbate and the substituent groups within.

Different methods designed to remove phenols have been proposed. Adsorption by activated carbons (ACs) is the best and most frequently used method. Other methods include, aerobic and anaerobic biodegradation, oxidation by ozone, and uptake by ion exchange resins, etc.AC possesses perfect adsorption ability for relatively low-molecular-weight organic compounds such as phenols. They can be manufactured in such a way that a highly fractal material is obtained, which is likewise roughly structured with each magnification and with pores of any width. There are two most common physical forms, in which activated carbon (AC) is used, i.e., powder-like AC and granular one. There are other forms, which are attracting increasing attention. Among them, fibers - mainly obtained from isotropic coal and petroleum pitch, cloths and felts [6].

As Bangladesh is an agricultural country, raw materials required for the preparation of activated carbon is available. The study of this research project is to prepare activated carbon using agricultural byproduct such as rice husk that has no economic value and evaluate its performance in the removal of phenol from aqueous environment.

\section{Material and Method}

\subsection{Instruments and Chemicals}

Shimadzu brand UV 2600 model UV vis spectrophotometer was used to determine phenol concentration in this study. Nabertherm brand P 330 was used for the preparation of Rice Husk activated carbon. JEDL brand JSM-7600F model Fluid Emission SEM was for taking the SEM image of activated carbon. Folin-Ciocalteu's phenol reagent was used to determine the concentration of phenol solutions. All other chemicals used in this study were analytical grade. 


\subsection{Preparation and Characterization of RHAC}

Activated carbons (ACs) were prepared from rice husks by following procedures: Firstly, the rice husks were washed with water to remove dirt and other contaminants, oven-dried at $110^{\circ} \mathrm{C}$ for $24 \mathrm{hr}$ then grounded and sieved to fractions with average particle size of $1 \mathrm{~mm}$. Secondly; the prepared husks were carbonized at $400^{\circ} \mathrm{C}$ under nitrogen flow for $90 \mathrm{~min}$. The resulting samples were impregnated with $\mathrm{NaOH}$ (weight ratio $1 / 3$ ) and dried at $120^{\circ} \mathrm{C}$ for $24 \mathrm{hr}$. Then, the preparative process was followed by heating at $200^{\circ} \mathrm{C}$ for 20 min under nitrogen atmosphere at a flow rate of $8 \mathrm{~L} / \mathrm{hr}$; thereafter the temperature was raised to $450^{\circ} \mathrm{C}$ and maintained the final temperature for $60 \mathrm{~min}$ to activate the obtained material. Finally, the activated product was grounded, neutralized by $0.1 \mathrm{M} \mathrm{HCl}$ solution and washed several times with hot distilled water to a constant $\mathrm{pH}$ of 7.0. The washed activated carbon samples were dried under vacuum at $120^{\circ} \mathrm{C}$ for $24 \mathrm{hr}$ and stored in desiccator used thereafter in this study.

RHAC's ash, moisture content, volatile matter, fixed carbon and iodine number determinations were performed according to Standard methods [7].

Boehm titration was used to determine lactonic, phenolic and carboxylic groups on the surface of RHAC. In this method, it is possible to distinguish various surface functional groups using $\mathrm{NaOH}$, $\mathrm{Na}_{2} \mathrm{CO}_{3}, \mathrm{NaHCO}_{3}$, where $\mathrm{NaOH}$ is considered to neutralize total surface acidic groups (lactonic, phenolic and carboxylic), $\mathrm{NaHCO}_{3}$ lactonic and carboxylic groups and $\mathrm{Na}_{2} \mathrm{CO}_{3}$ carboxylic groups, hence the quantity of these groups were calculated. For this purpose, $0.2 \mathrm{~g}$ of activated carbon is individually agitated with $0.1 \mathrm{M} 25 \mathrm{~mL} \mathrm{NaOH}, \mathrm{NaHCO}_{3}$ and $\mathrm{Na}_{2} \mathrm{CO}_{3}$ at $120 \mathrm{rpm}$ for $24 \mathrm{~h}$. Then, samples were filtered with vacuum filtration set up and collected in an erlenmeyer. Twenty milliliters of filtrates were titrated with $0.1 \mathrm{MHCl}$ and quantities of the surface functional groups were calculated $\left(\mathrm{mmol} \mathrm{g}^{-1}\right)$ [8]. The surface area of RHAC was calculated by applying the BET (Brunauer, Emmett and Teller) equation to $\mathrm{N}_{2}$ sorption isotherms.

\subsection{Adsorption Experiments}

In order to investigate the phenol adsorption, $300 \mathrm{mg}$ of $\mathrm{AC}$ was added into $100 \mathrm{~mL}$ phenol solutions with known concentrations and $\mathrm{pH}$ for a predetermined time at $27^{\circ} \mathrm{C}$. Phenol concentrations of the solutions obtained at the end of all adsorption studies were measured by a UV-vis spectrophotometer after appropriate dilutions. Concentration of phenol that remained unadsorbed in the solution was determined and percentage of adsorption and amount of phenol adsorbed per gram of AC were calculated by the following formulas, respectively [9],

$$
\begin{aligned}
& \text { Adsorption } \%=\frac{\left(\mathrm{C}_{0}-\mathrm{C}_{\mathrm{e}}\right)}{\mathrm{C}_{0}} \times 100----(1) \\
& \mathrm{q}_{\mathrm{e}}=\frac{\left(\mathrm{C}_{0}-\mathrm{C}_{\mathrm{e}}\right) \mathrm{V}}{\mathrm{m}}---------- \text { (2) }
\end{aligned}
$$

Where, $\mathrm{q}_{\mathrm{e}}$ is amount of phenol adsorbed per gram of AC $\left(\mathrm{mg} \mathrm{g}^{-1}\right) ; \mathrm{C}_{0}$ is initial phenol concentration $\left(\mathrm{mg} \mathrm{L}^{-1}\right) ; \mathrm{C}_{\mathrm{e}}$ is concentration of phenol that remained unadsorbed in the solution $\left(\mathrm{mg} \mathrm{L}^{-1}\right) ; \mathrm{V}$ is volume of phenol solution $(\mathrm{mL}) ; \mathrm{m}$ is amount of RHAC $(\mathrm{g})$.

\section{Results and Discussion}

\subsection{Characterization of AC}

Table 1 shows obtained results ofamounts of surface functional groups, moisture, volatile matter, fixed carbon and ash and iodine number, BET surface area values regarding the $\mathrm{AC}$ prepared with $\mathrm{NaOH}$ from Rice Husk.

Table 1.Properties of RHAC.

\begin{tabular}{lc}
\hline Proximate analysis $(\%)$ & \\
\hline Moisture & 5.77 \\
Volatile matter & 65.85 \\
Fixed carbon & 14.30 \\
Ashes & 14.08 \\
& \\
Iodine number $\left(\mathrm{mg} \mathrm{g}^{-1}\right)$ & 495.67 \\
BET surface area $\left(\mathrm{m}^{2} \mathrm{~g}^{-1}\right)$ & 306.70 \\
& \\
Surface functional groups $\left(\mathrm{mmol} \mathrm{g}^{-1}\right)$ & \\
Carboxylic & 7.734 \\
Phenolic & 1.061 \\
Lactonic & 0.242 \\
Total acidic value & 9.037 \\
\hline Adsorption
\end{tabular}

Adsorption properties of ACs depend on surface area and porous structure, as well as on ACs chemical structure to a large extent [10]. It is expected that RHAC could effectively adsorb phenol because of its high surface functional group content of the surface. High amount of ash is not desired because it reduces mechanical resistance and adsorption capacity of ACs [11]. Therefore, RHAC's low ash content is important. One of the basic properties of ACs is their high surface area. RHAC has considerable BET surface area like most of the ACs prepared from various plant-based materials by $\mathrm{NaOH}$ reported in the literature, which suggests that $\mathrm{RH}$ is a material that can be used to produce AC. Iodine number is an important parameter used to characterize adsorption performance of ACs as well as an indicator of activation grade. It can be concluded that RHAC has a moderate iodine number.

SEM images of RH and RHAC were obtained from JEDL brand JSM-7600F model Fluid Emission SEMand are shown in Figure 1 and Figure 2, respectively. When surface patterns and porous form of 
both carbons are compared with each other, it is apparent that the RHAC has a porous structure.

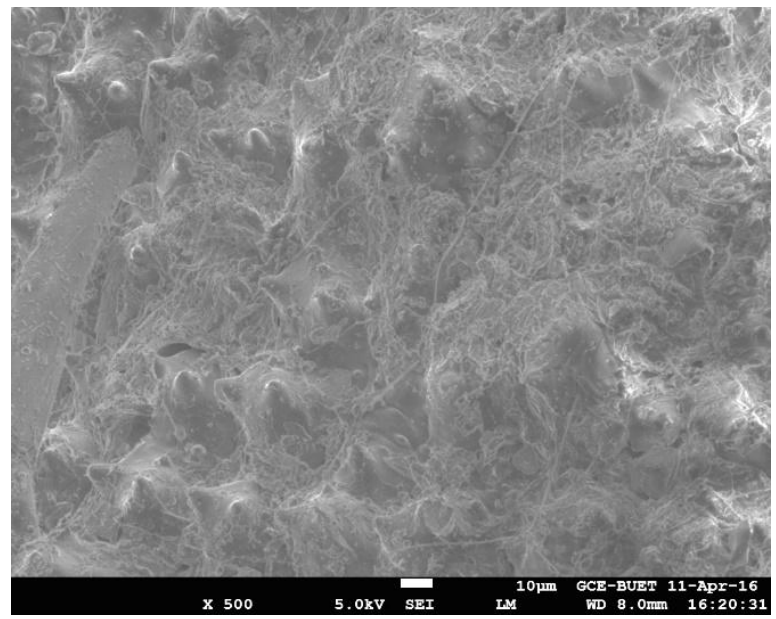

Figure 1.SEM image of Rice Husk surface.

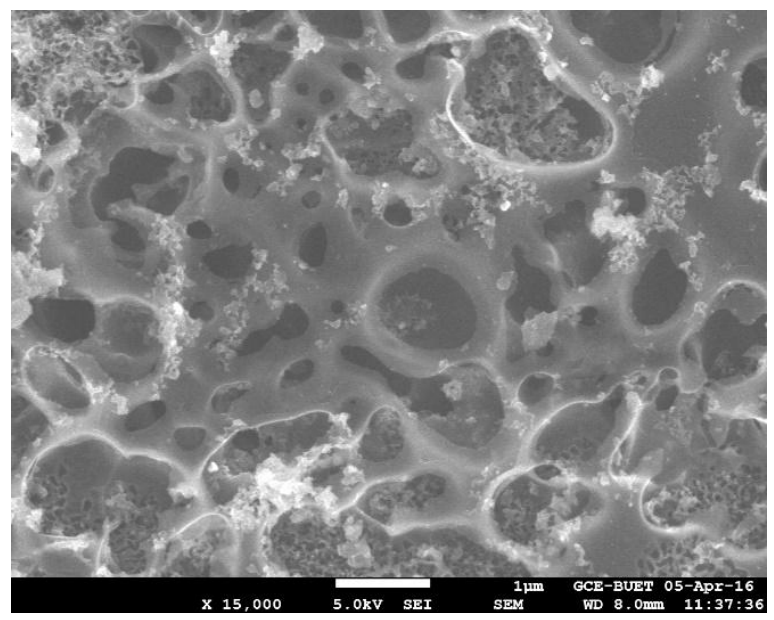

Figure 2. SEM image of Rice Husk Activated Carbon.

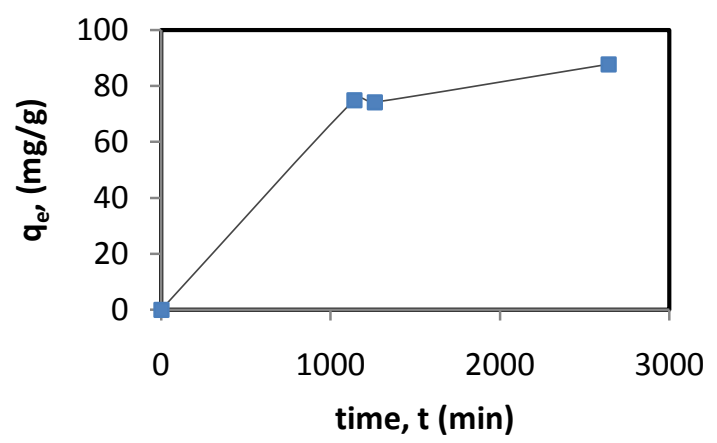

Figure 3.Adsorbed amounts of phenol at $27^{\circ} \mathrm{C}$ as a function of time for $200 \mathrm{ppm}$ initial concentration $(\mathrm{V}=100 \mathrm{~mL} ; \mathrm{m}=0.3 \mathrm{~g})$.

\subsection{Adsorption Kinetics}

The effect of time for adsorption process was carried out to determine the equilibrium point. Figure 3 shows the relationship of the amount of phenol adsorbed $(\mathrm{mg} / \mathrm{g})$ between contact time for $200 \mathrm{ppm}$ phenol concentrations at $27^{\circ} \mathrm{C}$. From the plot, it is found that the adsorption was rapid up to $1000 \mathrm{~min}$ and later onbecame slow, and finally the systems reached equilibrium around 2640 minute.

\subsubsection{Kinetic Modeling}

The mechanism of adsorption depends on the physical and chemical characteristics of the adsorbent as well as on the mass transport process. To investigate the adsorption process of phenol onto activated carbon, the adsorption rate data were analyzed using pseudo firstorder and pseudo second-order kinetic models.

The linearized forms of these equations are represented as

$$
\begin{aligned}
& \log \left(q_{e}-q_{t}\right)=\log q_{e}-\frac{k_{1}}{2.303} t------(3) \\
& \frac{\mathrm{t}}{\mathrm{q}_{\mathrm{t}}}=\frac{1}{\mathrm{k}_{2} \mathrm{q}_{\mathrm{e}}^{2}}+\frac{1}{\mathrm{q}_{\mathrm{e}}} \mathrm{t}-----------(4)
\end{aligned}
$$

Where, $\mathrm{q}_{\mathrm{e}}$ and $\mathrm{q}_{\mathrm{t}}$ are the amount of phenol adsorbed $(\mathrm{mg} / \mathrm{g})$ at equilibrium and at time $\mathrm{t}(\mathrm{min}), \mathrm{k}_{1}$ is the first order equilibrium rate constant $(1 / \mathrm{min}), \mathrm{k}_{2}$ the pseudo second order rate constant $(\mathrm{g} / \mathrm{mg} \mathrm{min})$. The pseudo first order and second order rate constants were evaluated from the linear plots of $\log \left(\mathrm{q}_{\mathrm{e}}-\mathrm{q}_{\mathrm{t}}\right)$ versus $\mathrm{t}$, and $\mathrm{t} / \mathrm{q}_{\mathrm{t}}$ versus $\mathrm{t}$, respectively.

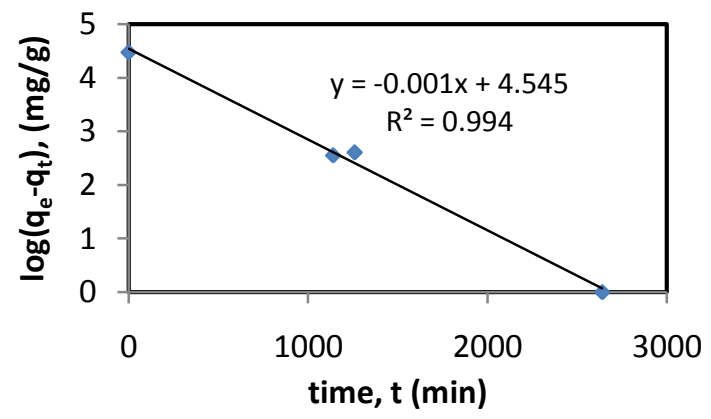

Figure 4.Pseudo first order kinetic model for the adsorption of phenol solution by RHAC.

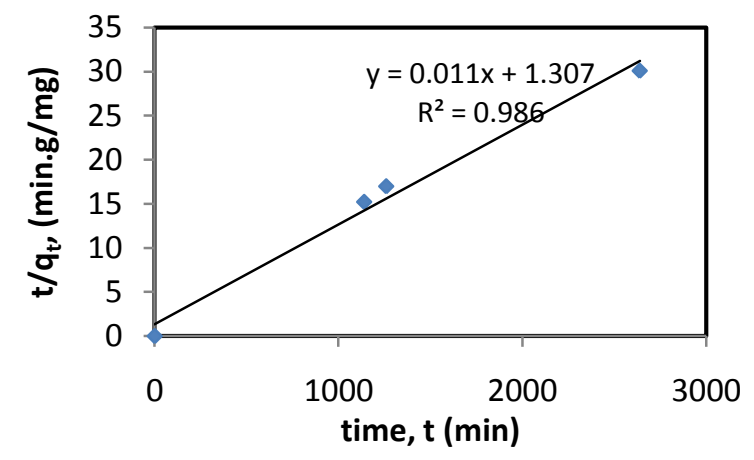

Figure 5.Pseudo second order kinetic model for the adsorption of phenol solution by RHAC.

The plots of pseudo first order and pseudo second order kinetic model are shown in Figure 4 and Figure 5 respectively 
Table 2. First order and second order parameters for $200 \mathrm{ppm}$ concentrations of $100 \mathrm{~mL}$ phenol solution

\begin{tabular}{|c|c|c|c|c|c|}
\hline \multirow{2}{*}{$\begin{array}{c}\mathrm{C}_{0} \\
\mathrm{mg} / \\
\mathrm{L}\end{array}$} & \multirow{2}{*}{$\begin{array}{c}\mathrm{q}_{\mathrm{e}}(\mathrm{ex} \\
\mathrm{p}) \\
\mathrm{mg} / \mathrm{g}\end{array}$} & \multicolumn{2}{|c|}{$\begin{array}{c}\text { Pseudo first } \\
\text { order }\end{array}$} & \multicolumn{2}{|c|}{$\begin{array}{c}\text { Pseudo } \\
\text { secondorder }\end{array}$} \\
\hline & & $\begin{array}{c}\mathrm{K}_{1} \times 10^{3} \\
\mathrm{~L} / \mathrm{min}\end{array}$ & $\begin{array}{c}\mathrm{q}_{\mathrm{e}} \\
(\mathrm{mg} / \mathrm{g})\end{array}$ & $\begin{array}{c}\mathrm{K}_{2} \times 10^{3} \\
(\mathrm{~min} \\
\mathrm{mg} / \mathrm{g})\end{array}$ & $\begin{array}{c}\mathrm{q}_{\mathrm{e}} \\
(\mathrm{mg} / \mathrm{g})\end{array}$ \\
\hline 200 & 87.8 & 3.915 & 94.17 & 0.0976 & 88.4 \\
\hline
\end{tabular}

The analysis of the $\mathrm{R}^{2}$ values shown in Figure $4 \& 5$ suggest that the experimental data fit the pseudo firstorder model with $\mathrm{R}^{2}$ value equal to 0.9948 than that of the pseudo second-order with $\mathrm{R}^{2}$ value 0.9969.The $\mathrm{q}_{\mathrm{e}}$ values calculated from pseudo first order kinetics relatively close to experimental values of $\mathrm{q}_{\mathrm{e}}$. For this reason, pseudo first order model better predicts the adsorption kinetics than the pseudo second-order model. Such a finding is also good agreement with previous studies.

\subsection{Phenol Adsorption Isotherms}

Langmuir [12] and Freundlich[13] isotherms are widely recognized and have been successfully applied to defining many adsorption equilibriums and evaluate adsorption equilibrium of metal ions and dyes from aqueous solutions. Therefore, phenol adsorption data were analyzed by Langmuir and Freundlich equations. These isotherms are defined by the following equations, respectively:

$$
\begin{aligned}
& \mathrm{q}_{\mathrm{e}}=\frac{\mathrm{q}_{\max } \mathrm{K}_{\mathrm{L}} \mathrm{C}_{\mathrm{e}}}{1+\mathrm{K}_{\mathrm{L}} \mathrm{C}_{\mathrm{e}}} \times 100----(5) \\
& \mathrm{q}_{\mathrm{e}}=\mathrm{K}_{\mathrm{F}} \mathrm{C}_{\mathrm{e}}^{\frac{1}{\mathrm{n}}}--------(6)
\end{aligned}
$$

Where, $\mathrm{K}_{\mathrm{L}}$ and $\mathrm{q}_{\max }$ are Langmuir constants related to free energy or adsorption enthalpy $\left(\mathrm{L} \mathrm{mg}^{-1}\right)$ and maximum monolayer adsorption capacity $\left(\mathrm{mg} \mathrm{g}^{-1}\right)$, respectively and Freundlich coefficients $n$ and $\mathrm{K}_{\mathrm{F}}$ are related to adsorption intensity and adsorption capacity, respectively [14] and [15]. Langmuir and Freundlich isotherms plotted for phenol adsorption on RHAC are shown in Figure 7 and Figure 8 respectively.

Table 3.Parameters of Langmuir and Freundlich isothermsfor phenol adsorption.

\begin{tabular}{cccc}
\hline \multicolumn{2}{c}{ Langmuir Constants } & \multicolumn{2}{c}{ Freundlich Constants } \\
\hline $\mathrm{q}_{\max }(\mathrm{mg} / \mathrm{g})$ & $\mathrm{K}_{\mathrm{L}}(\mathrm{L} / \mathrm{mg})$ & $\mathrm{K}_{\mathrm{F}}(\mathrm{mg} / \mathrm{g})$ & $\mathrm{n}$ \\
& & & \\
17.123 & 0.032 & 9.227 & 11.025 \\
\hline
\end{tabular}

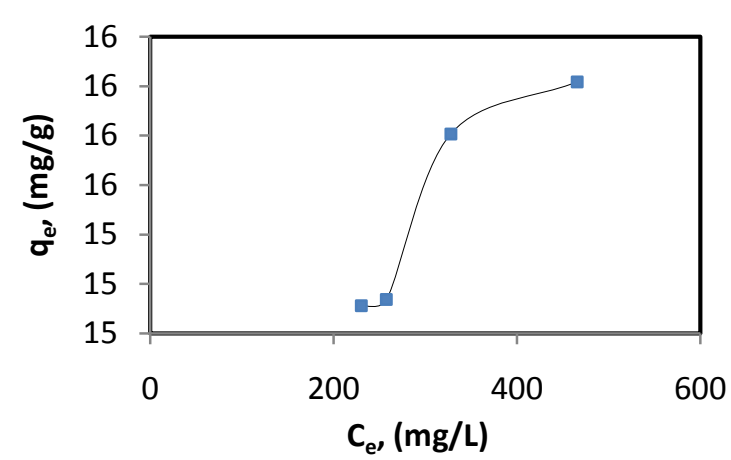

Figure 6. Experimental isotherm graph for adsorption of phenol by RHAC at $27{ }^{\circ} \mathrm{C}$ (initial phenol concentration, 200-500 mg/L; RHAC dosage, $300 \mathrm{mg}$; volume of MB solution, $100 \mathrm{~mL}$ ).

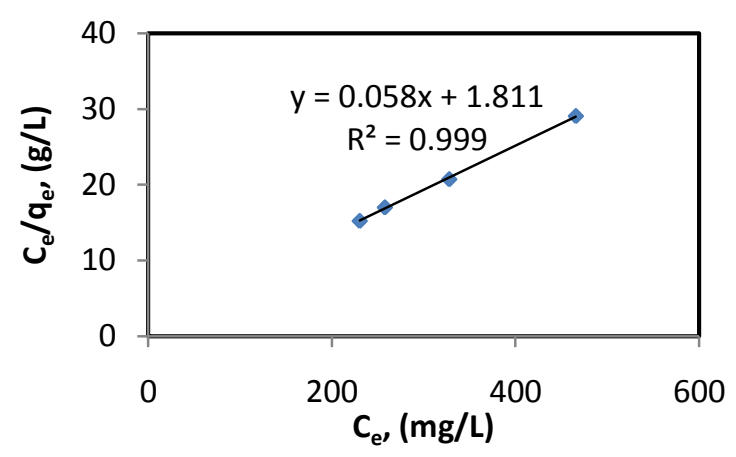

Figure 7. Langmuir isotherm graph for adsorption of phenol by RHAC at $27{ }^{\circ} \mathrm{C}$ (initial phenol concentration, 200-500 mg/L; RHAC dosage, $300 \mathrm{mg}$; volume of phenol solution, $100 \mathrm{~mL}$ ).

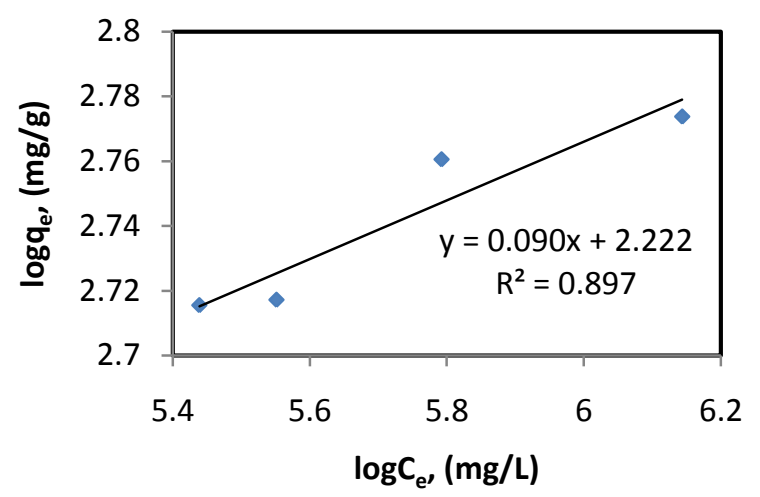

Figure 8. Freundlich isotherm graph for adsorption of phenol by RHAC at $27{ }^{\circ} \mathrm{C}$ (initial phenol concentration, 200-500 mg/L; RHAC dosage, $300 \mathrm{mg}$; volume of phenol solution, $100 \mathrm{~mL}$ ).

$\mathrm{q}_{\max }$ is the maximum adsorption capacity which was found $17.1233 \mathrm{mg} / \mathrm{g}$. The Langmuir and Freundlich isotherm model adequately describe the adsorption phenomenon of phenol though Freundlich isotherm is less applicable comparing to Langmuir and from the Langmuir parameter, a model isotherm (Figure 9) is generated. 


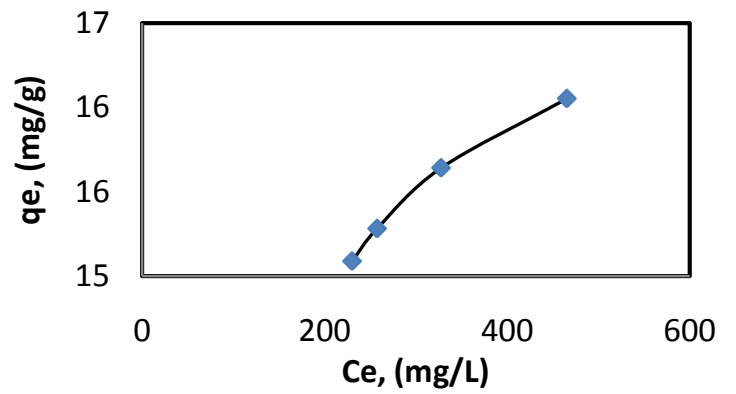

Figure 9. Langmuir model generated using obtained parameters from isotherm.

\section{Conclusion}

Activated carbon prepared from rice husk has a porous structure and high surface area. Phenol adsorption performance was investigated with batch adsorption and equilibrium capacity was found to be $17.123 \mathrm{mg} / \mathrm{g}$. The adsorption equilibrium isotherm is best described by the Langmuir model and its adsorption kinetics is best fitted by pseudo first order rate equation. It can be concluded that RHAC can be effectively used in the removal of phenol from aqueous environment. No doubt, it is an advantageous, practical and cost-effective method.

\section{Acknowledgement}

The authors express their deep gratitude to the BUET CASR for financial support to conduct this research.

\section{References}

1. Crauford, H.B. and G. Cline, Water Treatment Plant Design, In H. a. Crauford, New York, American Society of Civil Engineers, American Water Work Association, McGraw Hill (1990).

2. Mostafa MR, Sarma SE, Yousef AM, Removal of Organic Pollutants from Aqueous Solution, Part-1, Adsorption of Phenolby Activated Carbon, Indian J. Chem, 28A (1989):94-98.

3. Caturla F, Martin-Martinez J M, Molina-Sabio M et al., Adsorption of substituted phenols on activated carbon $[\mathrm{J}]$. J Coll Interface Sci,124 (1988): 528-534.

4. Kh.A. Halhouli, N.A. Darwish and N.m. Aldhoon, Effects of $\mathrm{pH}$ and inorganic salts on theadsorption of phenol from aqueous systems on activated decolorizing charcoal, Sep SciTechnol (1995).30 3313-24.

5. Patrick JW, Porosity in Carbons, New York, John Wiley \& Sons, Inc, 1995.

6. Rodriguez-Reinoso, F., Activated carbon: Structure Characterization Preparation and Applications, In: Marsh, H., Heintz, E.A., Rodriguez-Reinoso, F., (EDS), Introduction to Carbon technologies (1997), Chapter 2, P. 35.
7. Annual Book of ASTM Standards, Section 15, General Products, Chemical Specialities and End Use Products-Activated Carbon, vol. 15.01, ASTM International, West Conshohocken, PA, 1999.

8. Bingzheng Li, Charaterization of Pore Structure and Surface Chemistry of Activated Carbons - A Review, Fourier Transform - Materials Analysis, DrSalihSalih (Ed.) (2012), ISBN: 978-953-510594-7, InTech

9. S. Sivrikaya, S. Albayrak, M. Imamoglu, A. Gundogdu, C. Duran, H. Yildiz, Dehydrated hazelnut husk carbon: a novel sorbent for removal of $\mathrm{Ni}(\mathrm{II})$ ions from aqueous solution, Desalin. Water Treat., 50 (2012), pp. 2-13

10. G. Duman, Y. Onal, C. Okutucu, S. Onenc, J. Yanik, Production of activated carbon from pine cone and evaluation of its physical, chemical, and adsorption properties, Energy Fuel, 23 (2009), pp. 2197-2204

11. C. Castilla-Moreno, F. Marin-Carrasco, V.M. Ramon-Lopez, A.M. Merino-Alvarez, Chemical and physical activation of olive-mill waste water to produce activated carbons, Carbon, 39 (2001), pp. $1415-1420$

12. I. Langmuir, The adsorption of gases on plane surfaces of glass, mica and platinum, J. Am. Chem. Soc., 40 (1918), pp. 1361-1403

13. H.M.F. Freundlich, Uber die adsorption in losungen, Z. Phys. Chem., 57 (1906), pp. 385-470

14. J. Ghasemi, S. Asadpour, Thermodynamics' study of the adsorption process of methylene blue on activated carbon at different ionic strengths, J. Chem. Thermodyn., 39 (2007), pp. 967-971

15. H.B. Senturk, D. Ozdes, A. Gundogdu, C. Duran, M. Soylak, Removal of phenol from aqueous solutions by adsorption onto organomodifiedTirebolu bentonite: equilibrium, kinetic and thermodynamic study, J. Hazard. Mater., 172 (2009), pp. 353-362.

16. K. Vijayaraghavan, T.V.N. Padmesh, K. Palanivelu, M. Velan, Biosorption of nickel(II) ions onto Sargassumwightii: application of twoparameter and three parameter isotherm models, J. Hazard. Mater. B133 (2006) 304-308.

17. S. Kundu, A.K. Gupta, Arsenic adsorption onto iron oxide-coated cement (IOCC): regression analysis of equilibrium data with several isotherm models and their optimization, Chem. Eng. J. 122 (2006) 93-106.

18. A.B. Pérez-Marín, V. Meseguer Zapata, J.F. Ortuno, M. Aguilar, J. Sáez, M. Llorens, Removal of cadmium from aqueous solutions by adsorption onto orange waste, J. Hazard. Mater. B139 (2007) 122-131. 